\title{
Anterior reduction and C1-ring osteosynthesis with Jefferson-fracture reduction plate (JeRP) via transoral approach for unstable atlas fractures
}

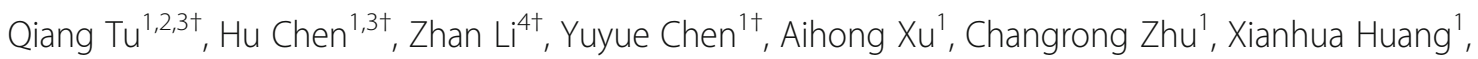
Xiangyang $\mathrm{Ma}^{1}$, Jianhua Wang ${ }^{1}$, Kai Zhang ${ }^{1}$, Qingshui Yin ${ }^{1}$, Jianzhong $\mathrm{Xu}^{2}$ and Hong $\mathrm{Xia}^{1,3^{*}}$ (D)

\begin{abstract}
Background: To introduce a novel transoral instrumentation in the treatment of unstable fractures of the atlas. Methods: From January 2008 to May 2018, 22 patients with unstable C1 fractures who received Jefferson-fracture reduction plate (JeRP) via transoral approach were retrospectively analyzed. The case history and the radiographs before and after surgery were noted. The type of fracture, the reduction of the fracture, and position of the internal fixation were assessed through preoperative and postoperative $\mathrm{CT}$ scans.

Results: All 22 patients successfully underwent anterior C1-ring osteosynthesis using the JeRP system, with a follow-up of $26.84 \pm 9.23$ months. Among them, 9 patients had transverse atlantal ligament (TAL) injury, including 3 in Dickman type I and 6 in type II. The preoperative lateral mass displacement (LMD) decreased from $7.13 \pm 1.46$ $\mathrm{mm}$ to $1.02 \pm 0.65 \mathrm{~mm}$ after the operation. Bone union was achieved in all patients without implant failure or loss of reduction. There were no surgery-related complications, such as wound infection, neurological deficit, or vertebral artery injury. However, atlantoaxial dislocation occurred in 3 patients with Dickman type I TAL injury 3 months postoperatively without any neurological symptoms or neck pain.
\end{abstract}

Conclusions: Transoral C1-ring osteosynthesis with JeRP is an effective surgical strategy to treat unstable atlas fractures with a safe, direct, and satisfactory reduction. The primary indication for the JeRP system is an unstable fracture (Gehweiler type I/III) or/ and TAL injury (Dickman type II).

Keywords: Atlas, Fractures, Transoral approach, Surgery, Osteosynthesis

\footnotetext{
* Correspondence: gzxiahong2@126.com

${ }^{+}$Qiang Tu, Hu Chen, Zhan Li contributed equally to this work and should be considered co-first authors.

'Department of Orthopaedics, PLA General Hospital of Southern Theatre Command: People's Liberation Army General Hospital of Southern Theatre Command, Guangzhou 510010, Guangdong, China

${ }^{3}$ The First School of Clinical Medicine, Southern Medical University, Guangzhou 510010, Guangdong, China

Full list of author information is available at the end of the article
}

(c) The Author(s). 2021 Open Access This article is licensed under a Creative Commons Attribution 4.0 International License, which permits use, sharing, adaptation, distribution and reproduction in any medium or format, as long as you give appropriate credit to the original author(s) and the source, provide a link to the Creative Commons licence, and indicate if changes were made. The images or other third party material in this article are included in the article's Creative Commons licence, unless indicated otherwise in a credit line to the material. If material is not included in the article's Creative Commons licence and your intended use is not permitted by statutory regulation or exceeds the permitted use, you will need to obtain permission directly from the copyright holder. To view a copy of this licence, visit http://creativecommons.org/licenses/by/4.0/. The Creative Commons Public Domain Dedication waiver (http://creativecommons.org/publicdomain/zero/1.0/) applies to the data made available in this article, unless otherwise stated in a credit line to the data. 


\section{Background}

The atlas has a unique ring structure with no vertebral body or spinous processes, which provides more flexibility and a greater range of motion (ROM) than other vertebrae of the spine [1]. As a transitional structure, it is an indispensable part of the craniovertebral junction, allowing the axial loading to be transferred from the occiput to the axis. The junctions of the lateral mass connected to both the anterior and posterior arches are relatively thinner, making them the weakest points of $\mathrm{C} 1$ and more susceptible to fracture [2]. That's why fractures with two or more breaks commonly occur in the C1-ring [3]. In general, the types of atlas fracture can be described as stable and unstable based on the integrity of transverse atlantal ligament (TAL) and adjacent vertebrae. Unstable $\mathrm{C} 1$ fractures are characterized by the high-grade transverse spread of lateral mass on an openmouth radiograph.

To date, posterior atlantoaxial and occipitocervical fusion techniques have been widely used in the treatment of unstable $\mathrm{C} 1$ fractures and have achieved satisfactory results [4]. However, posterior fusion techniques decrease the ROM of the craniocervical junction. Regarding this problem, the anterior C1-ring osteosynthesis is an appropriate option to safely and effectively perform ORIF via the transoral approach [5]. However, surgeons preferred the posterior C1-ring osteosynthesis to avoid surgical site infection, even if this technique cannot completely reduce and stabilize $\mathrm{C} 1$ anterior arch fractures. In 2004, Ruf [6] first reported a C1-C2 rotation function-preserving technique of $\mathrm{C} 1$ osteosynthesis via transoral approach, which not only enabled an anatomic reconstruction of the anterior arch of $\mathrm{C} 1$ but also achieved bony union. The study by $\mathrm{Ma}$ [2] demonstrated that the anterior technique of C1-ring ORIF with direct manipulation at the lateral masses was safe and effective for the treatment of highly unstable cases. However, the internal fixation device used in C1-ring osteosynthesis is not specialized for atlas fractures, and it is unlikely to achieve near anatomical reduction for $\mathrm{C} 1$ fracture directly and safely, particularly in the case of $\mathrm{C} 1$ anterior arch fractures. To our knowledge, there is no report on specialized apparatus for $\mathrm{C} 1$ osteosynthesis using a transoral approach.

In this study, we described a novel Jefferson-fracture reduction plate (JeRP) system (Wego Corporation, China) via the transoral approach. It is originally designed and clinically applied to treat unstable atlas fractures to preserve the motion function of the atlantoaxial joint.

\section{Methods}

This research program was approved by the institutional review committee of People's Liberation Army (PLA) General Hospital of Southern Theatre Command. Each patient signed a medical informed consent document preoperatively.

From Jan 2008 to May 2018, 22 patients with unstable C1 fractures who received JeRP via transoral approach were retrospectively analyzed. Patients with fractures of the adjacent vertebrae of the axis or occipital condyle were excluded. All patients suffered neck pain, stiffness, and limited range of motion in the neck. None of them had neurological deficit. On admission, all patients underwent preoperative $\mathrm{x}$-ray film, CT scans, and MRI (Figs. 1 and 2). The lateral mass displacement (LMD) of the atlas was measured from the coronal reconstructed view of the CT scans. The TAL integrity was evaluated
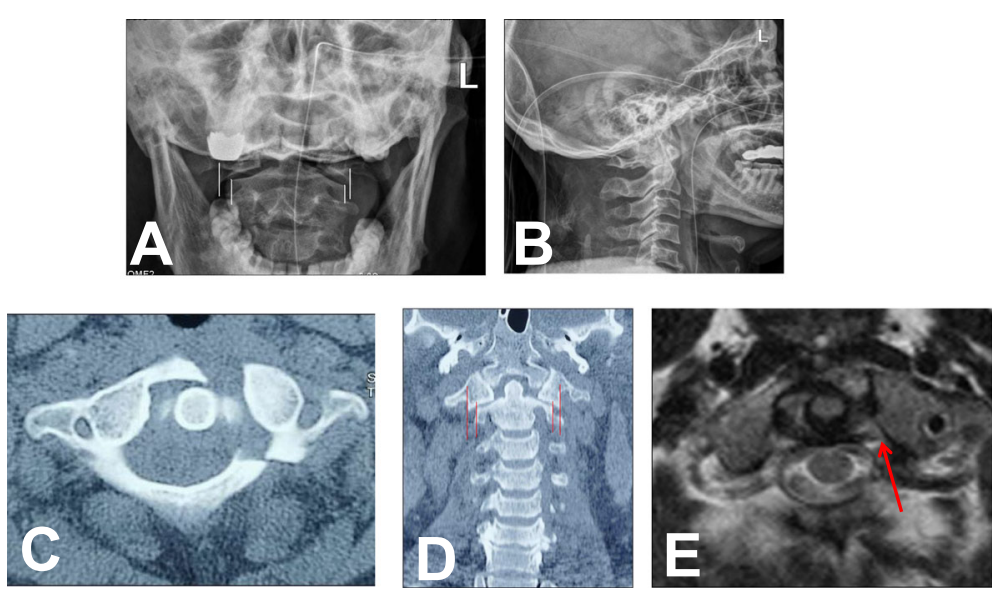

Fig. 1 A represent case (A, B, C, and $\mathbf{D})$ Preoperative X-ray and CT showed C1 fracture. C There were fracture lines in both anterior and posterior arches (Gehweiler type III). The LMD value measured on the open X-ray film was $7.28 \mathrm{~mm}(\mathbf{A})$, and the value measured on the coronal CT film was $6.54 \mathrm{~mm}(\mathbf{D})$. The MRI showed that the TAL had a high signal (red arrow) at the attachment point of the left lateral mass, considering an avulsion injury (Dickman type II). While compression of the spinal cord was not observed (E) 

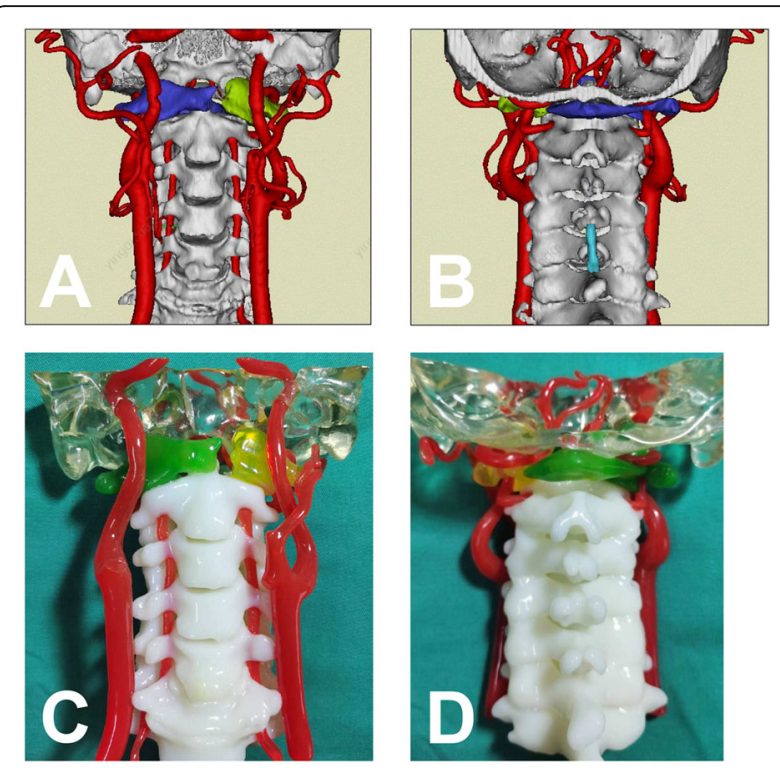

Fig. 2 3D reconstruction of anatomical digital model ( $\mathbf{A}$ and $\mathbf{B})$ and 1:1 scale 3D printed model of the cervical spine ( $\mathbf{C}$ and $\mathbf{D})$. The model showed that the fracture line of $\mathrm{C} 1$ was located at the junction of the left lateral mass and the anterior and posterior arches, and the fractured end (green and yellow, respectively) was shifted outwards (C and D)

by preoperative MRI. All patients underwent 4-6 kg skull traction preoperatively and intraoperatively in the hope that the displaced lateral mass might close at least partially.

\section{Design of the JeRP system}

The JeRP system consists of titanium alloy plates, selftapping screws, specialized repositor, and corresponding surgical instruments (Fig. 3). The JeRP plates shape like an " $\mathrm{L}$ ", which is consistent with the anatomical morphology in front of the atlas, and the lateral mass end of it is provided with two circular fixing holes fixed to the lateral mass of $\mathrm{C} 1$. On the side views, the plate has a slight arc, fitting the physiological curvature of $\mathrm{C} 1$. Additionally, there are two types of L-shaped plates, left and right, corresponding to $\mathrm{C} 1$ fractures with the fracture line closed to the left or right lateral mass respectively. The middle of the system is a long-elliptic hole in which a temporary reduction screw can slide. Notably, with the help of the specialized repository, the compression force can be gently applied to pull together the fractured ends for reduction. The working principle of the JeRP system in the treatment of $\mathrm{C} 1$ fracture is shown in Fig. 4.

\section{Surgical technique}

All surgeries were performed by senior spine surgeons. Under general anesthesia with transnasal endotracheal intubation, the patients were placed in a supine position with skull traction weighing 4-6 kg. Codman oral

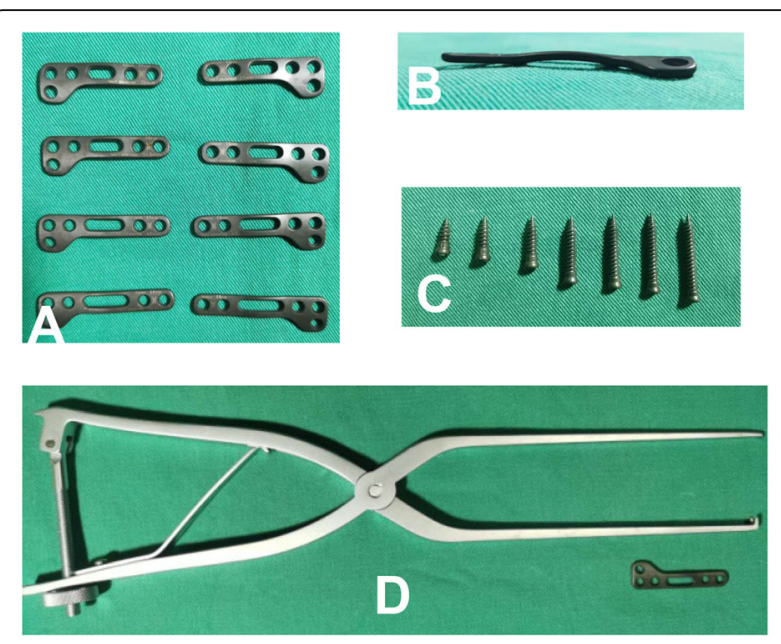

Fig. 3 Different views of the JeRP system. Top and side views of titanium alloy plate (A and $\mathbf{B}$ ). There are two types of L-shaped plates, left and right, corresponding to $\mathrm{C} 1$ fractures with the fracture line closed to the left or right lateral mass (A). The plate has a slight arc, fitting the physiological curvature of C1 (B). Different sizes of self-tapping screws (C) and the JeRP specialized repositor were shown (D)

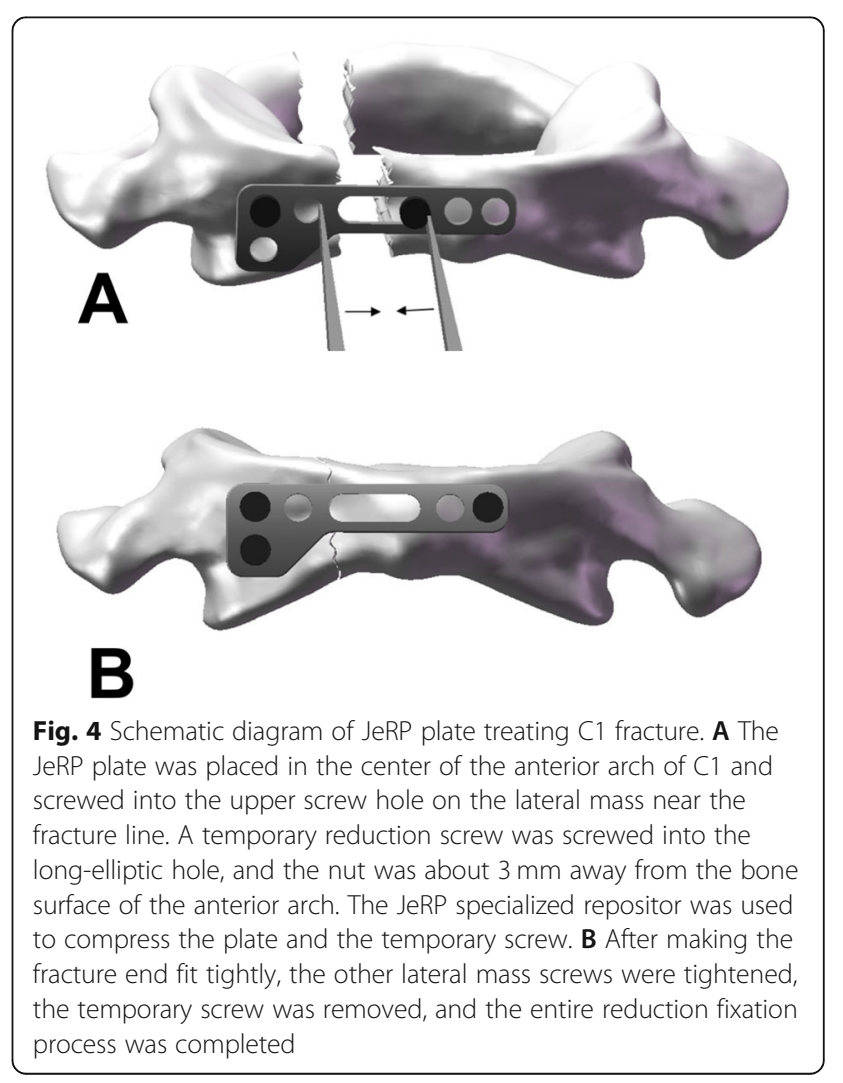


retractor was used to expose the oropharynx. A 3-4 cm longitudinal midline incision along the posterior pharyngeal wall was made, and the soft tissue was dissected to fully expose the surgical field, including the anterior arch, fragment bone, and lateral mass of atlas (Fig. 5A). The ideal entry point, the trajectory of the screw, and the length of the JeRP plates were determined based on the preoperative CT measurement. The anterior tubercle of $\mathrm{C} 1$ was polished with a high-speed drill. After removing the soft tissue between bony fragments, the JeRP plate was placed in the anterior aspect of the atlas (Fig. 5B). By palpating the medial edge and lower margin of the lateral mass, we could determine the optimal entry point of the screws. First, one lateral mass screw close to the fracture line was installed and tightened to stabilize the plate. Then, a temporary reduction screw was placed in the anterior arch of $\mathrm{C} 1$, which could be moved in the runner of the plate, and the nut was about $3 \mathrm{~mm}$ away from the bone surface of the anterior arch. The specialized repositor was installed between a temporary screw and the complex comprising the lateral mass and the plate (Fig. 5C, D). The compression force was gently applied via the specialized repositor to pull together the fractured ends and make them fit tightly. Next, the other lateral mass screws were tightened, the temporary screw was removed, and the entire reduction fixation process was completed. Finally, the JeRP plate was affixed to the anterior arch, with the intraoperative fluoroscopy confirming that the reduction of fracture and position of internal fixation were satisfying. After completing the JeRP implant procedure, the wound was soaked with povidoneiodine for $15 \mathrm{~min}$ and then was closed in the muscular and mucosal layers respectively with interrupted sutures.

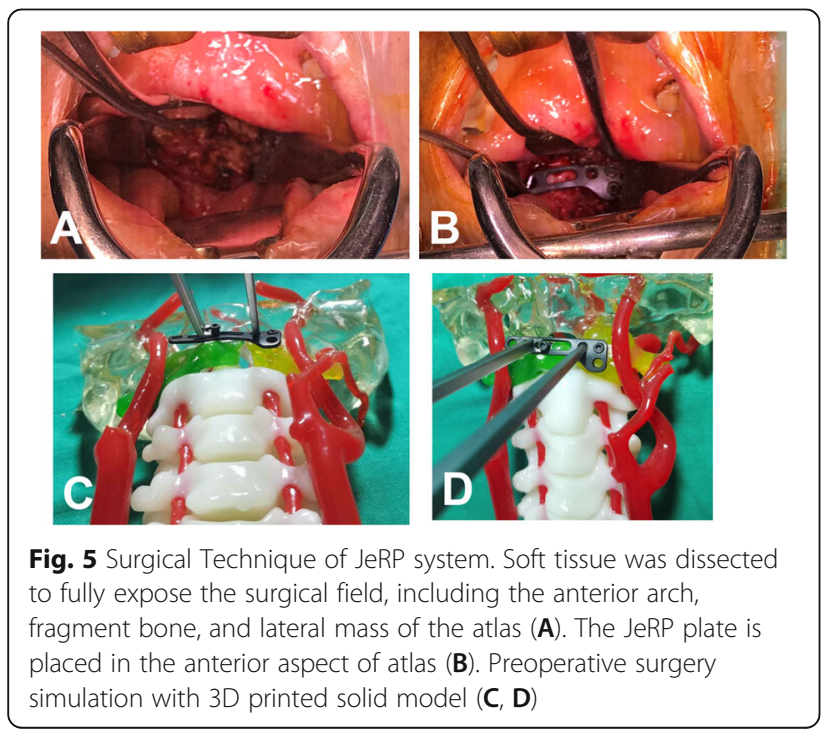

\section{Postoperative treatment}

The transnasal endotracheal catheter was maintained for 2 days after the operation, and a nasogastric feeding tube was kept for 1 week. The fluid diet was started after the removal of the nasogastric tube and the normal diet was resumed 3 weeks postoperatively. All patients were given 5- to 7-day intravenous antibiotics as preventive interventions after surgery and kept a neck collar for 3 months. Postoperative CT was used to assess the efficacy of the $\mathrm{C} 1$ reduction and the accuracy of the screw placement. What's more, CT scans and X-ray film of the cervical spine were performed at the third, sixth, and twelfth months after surgery to evaluate bony healing, reduction, and stability of the $\mathrm{C} 1-\mathrm{C} 2$ (Fig. 6). At the final follow-up, the atlanto-dens interval (ADI) was calculated based on flexion-extension radiographs. Furthermore, a visual analogue scale (VAS) was performed to evaluate the degree of neck pain.

\section{Results}

The demographic data of patients were listed in Table 1. The incision of the posterior pharyngeal wall in all patients was well-healed without any infection or dehiscence. No vertebral artery or spinal cord injury occurred during the operation. According to Gehweiler's classification system, 7 of 22 patients presented with type I fractures, and 15 of 22 patients had type III fractures. The C1-rings were separated into various number of fragments, including 2 separate fragments (in 7 patients), 3 fragments (in 13 patients), and 4 fragments (in 2 patients). Nine patients had confirmed TAL injury (3 had type I and the rest had type II based on Dickman's classification), while the other 13 patients had no or unconfirmed TAL injury. The surgical and clinical outcomes were listed in Tables 2 and 3. All operations were completed successfully without surgeryrelated complications, such as wound infection, neurological deficit, or vertebral artery injury. The preoperative LMD decreased from $7.13 \pm 1.46 \mathrm{~mm}$ to $1.02 \pm 0.65 \mathrm{~mm}$ after the operation. Bone union was achieved in all patients without implant failure or loss of reduction. At the final follow-up, the mean VAS score was $0.28 \pm 0.13$ points. Moreover, the upper cervical range of motion in all patients was well preserved. However, 3 patients had an ADI of more than $4 \mathrm{~mm}$ at the last follow-up without any neurological symptoms or neck pain. One patient had limited cervical movement due to the penetration of the atlanto-occipital facet with lateral mass screws but didn't receive any special treatment because it didn't cause any obvious pain. 

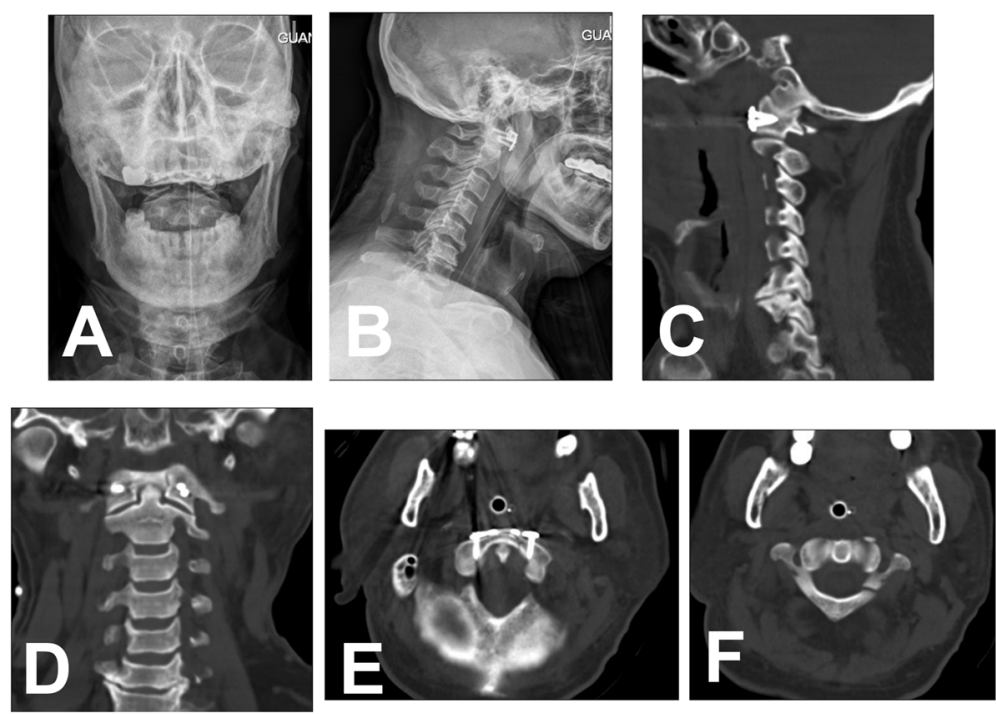

Fig. 6 Postoperative X-ray and CT showed a good position of the JeRP plate (A, B, C, D, and E). CT scan showed that the preoperative LMD decreased from $6.54 \mathrm{~mm}$ to $0 \mathrm{~mm}$ after the surgery (D), and C1 fracture was anatomically reduced (E and $\mathbf{F})$

\section{Discussion}

Most stable atlas fractures can be treated conservatively [7]. As for unstable $\mathrm{C} 1$ fractures, surgical strategies have become the standard of care. Unstable atlas fracture is usually accompanied by TAL injury, presenting as separation of the lateral masses, and subluxation or dislocation of atlantoaxial joint [5]. There is also a point that it was atlas fractures, instead of $\mathrm{C} 1$ posterior arch fractures, that destroyed the stability of the upper cervical spine. The displacement of bone fragments or atlantoaxial dislocation puts the spinal cord in danger and can result in severe complications like paraplegia or even death $[8,9]$. The goal of the treatment is to reduce the fracture, correct dislocated fracture, stabilize the atlantoaxial joint, and preserve the maximum ROM of the upper cervical spine [10, 11]. However, the surgical strategies for unstable $\mathrm{C} 1$ fractures are still controversial.

Table 1 Demographic Data

\begin{tabular}{ll}
\hline Variables & N \\
\hline Sex (Male, $n$ ) & $22(12)$ \\
Age (years) & $32 \sim 67$ \\
Follow-up time (months) & $26.84 \pm 10.23$ \\
Type of fractures (n) & \\
Type I & 7 \\
Type III & 15 \\
Other types & 0 \\
TAL injury & \\
$\quad$ Type I & 3 \\
Type II & 6 \\
$\quad$ Uncertain & 13 \\
\hline
\end{tabular}

Value of C1-ring osteosynthesis in unstable atlas fracture Conservative therapy in unstable atlas fracture for several months may lead to severe discomfort and a high incidence of bony nonunion [12]. Simultaneously, the inconsistency and mechanical instability of the occipitocervical junction may restrict motion and cause persistent neck pain [13]. To date, the posterior atlantoaxial or occipitocervical fusion is supposed to be the main surgical method, but it will result in limited range of motion of the upper cervical spine. The ideal treatment method is limited fixation without restricting the ROM of the upper cervical spine [14]. For this, many spine surgeons gave up the posterior fusion and preferred C1-ring osteosynthesis $[15,16]$. The question regarding the relationship between C1-ring osteosynthesis and the integrity of the TAL is still controversial. Traditionally, the integrity of TAL is the key to determining the stability of $\mathrm{C} 1$ fractures. The rule of Spence [17] showed that total LMD over $6.9 \mathrm{~mm}$ on open-mouth radiographs correlated with rupture to TAL had important clinical

Table 2 Surgical outcomes

\begin{tabular}{ll}
\hline $\begin{array}{l}\text { Variables } \\
\text { (min) }\end{array}$ & \\
$\begin{array}{l}\text { Blood loss } \\
(\mathrm{ml})\end{array}$ & $144.21 \pm 155.67$ \\
$\begin{array}{l}\text { Hospital } \\
\text { stay(d) }\end{array}$ & $19.00 \pm 10.55$ \\
$\begin{array}{ll}\text { Complications } & 1 \text { patient had limited cervical movement due to the } \\
\text { penetration of the atlanto-occipital facet with lateral } \\
\text { mass screws, but no obvious pain and no special treat- } \\
\text { ment. No surgery-related complications,such as wound } \\
\text { infection, neurological deficit, or vertebral artery injury. }\end{array}$ \\
\hline
\end{tabular}


Table 3 Clinical outcomes

\begin{tabular}{lcccc}
\hline Parameters & Preoperative & Postoperative & Follow-up & $P$ \\
\hline LMD $(\mathrm{mm})$ & $7.13 \pm 1.46$ & $1.02 \pm 0.65$ & $0.53 \pm 0.21$ & $<0.0001$ \\
VAS & $7.42 \pm 3.92$ & $2.17 \pm 1.33$ & $0.28 \pm 0.13$ & $<0.0001$ \\
Complications & $\begin{array}{l}\text { 3 patients with Dickman type I TAL injury occured atlantoaxial dislocation } 3 \text { months postoperatively without any neurological } \\
\text { symptoms or neck pain }\end{array}$ & & \\
\hline
\end{tabular}

value in determining whether surgical intervention was needed, but this is currently being questioned. What's more, other tissues can help maintain $\mathrm{C} 1-\mathrm{C} 2$ stability and restrict motion despite rupture of TAL. Some scholars' findings have shown that the significance of axial ligamentous tension of craniocervical junction has been underrated [18]. Because of its unique anatomical structure and biomechanical environment, the occipitocervical junction is mainly stabilized by the ligamentous complex of $\mathrm{C} 0-\mathrm{C} 1-\mathrm{C} 2$ [13]. Previous literature has shown that $\mathrm{C} 1$ burst fractures are axial load injury for which the integrity of secondary stabilizers comprising the alar ligaments, facet capsule, and neck musculature is easier to maintain. C1-ring osteosynthesis techniques can restore the axial tension of the ligamentous complex of $\mathrm{C} 0-\mathrm{C} 1-\mathrm{C} 2$ through the reduction of the fracture. Studies have shown that even with the rupture of TAL, C1-ring osteosynthesis can provide sufficient stability under physiological load. Thus, incompetence of TAL may not be a contraindication to C1-ring osteosynthesis. The conventional definition of $\mathrm{C} 1$ instability based on the integrity of TAL underestimates the number of fractures requiring surgical intervention and overestimates the number of fractures requiring $\mathrm{C} 1-\mathrm{C} 2$ fusion.

\section{Advantage of anterior C1-ring osteosynthesis using JeRP system}

C1-ring osteosynthesis using both posterior and transoral approaches has been published [18]. With posterior C1-ring osteosynthesis techniques, posterior arch fracture and the lateral mass displacement could be satisfactorily reduced by the compression force on the end of bilateral mass screws. However, it makes the front of the lateral mass screw swing laterally, leading to insufficient reduction of anterior arch fracture of C1 [19]. In addition, complications of this approach are related to the technical difficulty of obtaining a direct reduction and potential for residual postoperative stiffness relating to the approach. In all, with limited retrospective data, it is difficult to verify the effectiveness of $\mathrm{C} 1$ osteosynthesis between posterior and transoral approaches without comparative studies and larger cohort size.

Anterior direct reduction of the atlas fractures promotes the rate of bony union of fractures by improving the integrity of the $\mathrm{C} 0-\mathrm{C} 1-\mathrm{C} 2$ complex structure. This approach has a good safety profile, avoiding the fusion of important motion segments while restoring the C0C2 height. Results of transoral C1-ring osteosynthesis for unstable atlas fractures have been verified over the last decade. However, many surgeons are hesitant about this technique because of unfamiliarity with the transoral approach, the theoretically increased risk of infection. The universal shortcoming of transoral $\mathrm{C} 1$ osteosynthesis published previously is that reduction of $\mathrm{C} 1$ fracture is only an acceptable repair rather than anatomical reconstruction. The transoral C1-ring osteosynthesis is technically challenging, and there are no specialized devices or spinal implants designed for treating unstable atlas fractures. The main problem with current techniques is that the posterior pharyngeal soft tissue is not thick enough to cover the plate or rod, thus increasing the risk of wound complications. Additionally, it is difficult to implement a satisfactory reduction of atlas fractures in deep and narrow space. Meanwhile, the end of the lateral mass screw via transoral approach is too high, which is likely to result in the crack of the wound of the posterior pharyngeal wall or postoperative dysphagia. In this study, the JeRP system is introduced for anterior C1-ring osteosynthesis. The advantage of this system lies in the use of a dedicated reduction instrument, which can not only satisfy the reduction of the fracture end but also place the fixation screws in the fracture reduction state without being affected by the reduction instrument. It is generally acceptable to follow the principle that the screws don't penetrate the edge of the lateral mass into the atlanto-occipital joint or enter the atlantoaxial joint. The lateral mass is wedge-shaped, with higher external and lower internal structures. The screw has an internally deviated insertion point, allowing the screw to easily enter the joint. In our paper, 1 lateral mass screw was observed to enter the atlanto-occipital joint. In the series, 22 patients had bone fusion without any wound infection and dehiscence being observed. The main advantage of the JeRP system is that it can ideally reduce the $\mathrm{C} 1$ fracture via the anterior approach and the inserted plate and screws will not interfere with the midline wound closure. The inconsistency of the $\mathrm{C} 0-\mathrm{C} 1$ and $\mathrm{C} 1-\mathrm{C} 2$ joints is rectified, and the ligamentous tension band of the craniocervical junction is regained as well. As far as we know, this new technology can minimize lateral mass displacement. The JeRP system appears to be a safe and effective method to deal with unstable $\mathrm{C} 1$ 
fractures. It can achieve ideal bone fusion and preserve the range of motion of the craniocervical junction.

The JeRP system was designed for treating unstable $\mathrm{C} 1$ fractures without affecting the TAL, and its indication is very narrow. In the actual process, we also applied the JeRP system to $\mathrm{C} 1$ fractures with TAL rupture, and achieved satisfactory results. Among them, 3 patients with Dickman type I TAL injury suffered atlantoaxial dislocation postoperatively, while the patients with Dickman type II TAL injury had good effect. Hence, the primary indication for the JeRP system is an unstable $\mathrm{C} 1$ fracture (Gehweiler type I/III) with or without TAL injury (Dickman type II).

\section{Limitations}

Limitations of this paper include the lack of quantified range for preserving the motion of atlantooccipital and atlantoaxial joints, small sample size, retrospective design, and the possibility of selection bias.

\section{Conclusions}

Transoral C1-ring osteosynthesis with the JeRP system is an effective option for treating unstable $\mathrm{C} 1$ fractures and can achieve safe, direct, and satisfactory reduction. Even if the TAL is ruptured, the atlantoaxial joint can remain relatively stable. TAL injury may not necessarily be an absolute contraindication for ORIF for atlas fracture. However, further studies are needed to investigate the long-term effect of atlantoaxial instability.

\section{Abbreviations}

JeRP: Jefferson-fracture reduction plate; LMD: Lateral mass displacement; TAL: Transverse atlantal ligament; ADI: Atlanto-dens interval; VAS: Visual analogue scale

\section{Supplementary Information}

The online version contains supplementary material available at https://doi. org/10.1186/s12891-021-04628-4.

\section{Additional file 1.}

\section{Acknowledgements}

Not Applicable.

\section{Authors' contributions}

All authors contributed to the surgery that the data collected from. The first draft of the manuscript was written by QT. Data collection and analysis were performed by $\mathrm{HC}$ and $\mathrm{ZL}$. Interpretation of data was performed by $\mathrm{YC}, \mathrm{AX}$, CZ and XH. XM, JW, KZ, QY, JX and HX had substantively revised it. All authors read and approved the final manuscript.

\section{Funding}

(1)Military Medical Science and Technology Youth Cultivation Program Incubation Project (NO.19QNP040); (2)the Science and Technology Planning Project of Guangzhou City (NO.201904010349) 3PhD projects of Third Military Medical University (NO.JSKT201904).(4) Army Logistics Research Project of PLA (CLB20J033). All the funders are QT. The funding bodies played no role in the design of the study and collection, analysis, and interpretation of data and in writing the manuscript.

\section{Availability of data and materials}

The datasets generated during and analyzed during the current study are not publicly available due to them containing information that could compromise research participant privacy/consent, but are available from the corresponding author on reasonable request.

\section{Declarations}

Ethics approval and consent to participate

This research program was approved by the institutional review committee of People's Liberation Army (PLA) General Hospital of Southern Theatre Command. Approval number: PLA GHOSSTC 2019051. Each patient signed a medical informed consent document preoperatively.

\section{Consent for publication}

All patients gave written informed consent for publication of data.

\section{Competing interests}

$\mathrm{NO}$

\section{Author details}

${ }^{1}$ Department of Orthopaedics, PLA General Hospital of Southern Theatre Command: People's Liberation Army General Hospital of Southern Theatre Command, Guangzhou 510010, Guangdong, China. ${ }^{2}$ Department of Orthopaedics, Southwest Hospital, Third Military Medical University, Chongqing 400038, China. ${ }^{3}$ The First School of Clinical Medicine, Southern Medical University, Guangzhou 510010, Guangdong, China. ${ }^{4}$ Guangzhou University of Chinese Medicine, Guangzhou 510006, Guangdong, China.

Received: 21 December 2020 Accepted: 18 August 2021

Published online: 30 August 2021

\section{References}

1. Wang J, Zhou Y, Zhang ZF, et al. Direct repair of displaced anterior arch fracture of the atlas under microendoscopy: experience with seven patients. Eur Spine J. 2012;21:347-51.

2. Ma WH, Xu NJ, Hu Y, et al. Unstable atlas fracture treatment by anterior plate C1-ring osteosynthesis using a transoral approach. Eur Spine J. 2013; 22:2232-9.

3. Zou XB, Ouyang BP, Wang BB, et al. Motion-preserving treatment of unstable atlas fracture: transoral anterior C1-ring osteosynthesis using a laminoplasty plate. BMC Musculoskelet Disord. 2020;21:538.

4. Laubach M, Pishnamaz M, Scholz M, et al. Interobserver reliability of the Gehweiler classification and treatment strategies of isolated atlas fractures: an internet-based multicenter survey among spine surgeons. Eur J Trauma Emerg Surg. 2020. https://doi.org/10.1007/s00068-020-01494-y.

5. Guo W, Lin Y, Huang JW, et al. Treatment strategy of unstable atlas fracture: a retrospective study of 21 patients. Medicine (Baltimore). 2020;99:e20153.

6. Ruf M, Melcher R, Harms J. Transoral reduction and osteosynthesis C1 as a function-preserving option in the treatment of unstable Jefferson fractures. Spine. 2004;29:823-7.

7. Bednar DA, Almansoori KA. Solitary C1 posterior fixation for unstable isolated atlas fractures: case report and systematic review of the literature. Glob Spine J. 2016;6:375-82.

8. Fiedler N, Spiegl UJA, Jarvers JS, et al. Epidemiology and management of atlas fractures. Eur Spine J. 2020;29:2477-83.

9. Schleicher P, Scholz M, Kandziora F, et al. Recommendations for the diagnostic testing and therapy of atlas fractures. Z Orthop Unfall. 2019;157: 566-73.

10. Kandziora F, Scholz M, Pingel A, et al. Treatment of atlas fractures: recommendations of the spine section of the German Society for Orthopaedics and Trauma (DGOU). Global Spine J. 2018;8:5S-11S.

11. Smith RM, Bhandutia AK, Jauregui JJ, et al. Atlas fractures: diagnosis, current treatment recommendations, and implications for elderly patients. Clin Spine Surg. 2018;31:278-84.

12. Zhao ZS, Wu GW, Lin J, et al. Management of Combined Atlas Fracture with type II odontoid fracture: a review of 21 cases. Indian J Orthopaed. 2019;53: $518-24$

13. Zhang YS, Zhang JX, Yang QG, et al. Posterior osteosynthesis with monoaxial lateral mass screw-rod system for unstable C1 burst fractures. Spine J. 2018;18:107-14. 
14. Hu Y, Xu RM, Albert TJ, et al. Function-preserving reduction and fixation of unstable Jefferson fractures using a C1 posterior limited construct. J Spinal Disord Tech. 2014;27:E219-25.

15. Ottenbacher A, Bettag M. Resolution of traumatic vertebral artery dissection and occlusion after repositioning and posterior C1-ring osteosynthesis of a displaced Jefferson burst fracture. Acta Neurochir. 2017;159:1561-4.

16. Koller $\mathrm{H}$, Resch HM, et al. A biomechanical rationale for C1-ring osteosynthesis as treatment for displaced Jefferson burst fractures with incompetency of the transverse atlantal ligament. Eur Spine J. 2010;19: 1288-98.

17. Woods RO, Inceoglu S, Akpolat YT, et al. C1 lateral mass displacement and transverse Atlantal ligament failure in Jefferson's fracture: a biomechanical study of the "rule of Spence". Neurosurgery. 2018;82:226-31.

18. Shatsky J, Bellabarba C, Nguyen Q, et al. A retrospective review of fixation of C1 ring fractures--does the transverse atlantal ligament (TAL) really matter? Spine J. 2016;16:372-9.

19. Kandziora F, Chapman JR, Vaccaro AR, et al. Atlas fractures and atlas osteosynthesis: a comprehensive narrative review. J Orthop Trauma. 2017;31 Suppl 4:S81-S89.

\section{Publisher's Note}

Springer Nature remains neutral with regard to jurisdictional claims in published maps and institutional affiliations.

Ready to submit your research? Choose BMC and benefit from:

- fast, convenient online submission

- thorough peer review by experienced researchers in your field

- rapid publication on acceptance

- support for research data, including large and complex data types

- gold Open Access which fosters wider collaboration and increased citations

- maximum visibility for your research: over $100 \mathrm{M}$ website views per year

At BMC, research is always in progress.

Learn more biomedcentral.com/submissions 